\title{
AVALIAÇÃO DE IMPACTO AMBIENTAL COMO INSTRUMENTO DE ESTÍMULO À PRODUÇÃO LIMPA: DESAFIOS E OPORTUNIDADES NO ESTADO DA BAHIA
}

\author{
Márcia Mara de Oliveira Marinho \\ Doutora em Ciências Ambientais pela Universidade de East Anglia - UEA \\ Professora de Pós-Graduação na Universidade Federal da Bahia- UFBA \\ marma@ufba.br
}

Severino Soares Agra Filho

Doutor em Economia Aplicada pela Universidade Estadual de Campinas - UNICAMP marma@ufba.br

Silvio Roberto Magalhães Orrico

Doutor em Saúde Pública pela Universidade Federal de São Paulo - USP srm.orrico@gmail.com

\section{Fernanda Curvelo Santos}

Engenheira Sanitarista e Ambiental pela Universidade Federal da Bahia - UFBA fcurvelo@hotmail.com

\section{RESUMO}

A Avaliação de Impacto Ambiental (AIA) é um instrumento de política pública que tem por objetivo subsidiar o planejamento e a tomada de decisão quanto à implantação de atividades com potencial de causar danos ao ambiente, buscando alternativas mais adequadas e orientando a gestão ambiental. A Produção Limpa (PL) busca mecanismos para aumentar a ecoeficiência dos processos e produtos e reduzir riscos ao meio ambiente e aos seres vivos. Este artigo levanta possibilidades para aprimoramento das diversas etapas do processo da AIA por meio da inserção da abordagem da Produção Limpa. Esta reflexão foi feita com base em análise documental de alguns estudos de caso no Estado da Bahia e entrevistas conduzidas com representantes do órgão ambiental. Apresenta-se, por meio deste artigo, critérios e procedimentos para a inclusão da PL na AIA. Os resultados indicam que há diversas oportunidades para obtenção de alternativas tecnológicas e práticas de gestão com foco na PL nas diversas etapas da Avaliação de Impacto Ambiental e que não têm sido devidamente utilizadas.

Palavras-chave: Avaliação de impacto ambiental; Gestão ambiental; Produção limpa.

\section{ENVIRONMENTAL IMPACT ASSESSMENT AS A TOOL TO SUPPORT CLEANER PRODUCTION: CHALLENGES AND OPPORTUNITIES IN BAHIA STATE}

\begin{abstract}
Environmental Impact Assessment is a public policy tool that aims to help the decision making and management related to implementation of activities with potential to cause significant damage to the environment. Clean Production is an approach to pursue eco-efficiency of process and products, reducing risks to the environment and life. This paper presents some criteria and opportunities to integrate $\mathrm{CP}$ in several stages of the EIA process. Methodology included analysis of documents of projects submitted to EIA in the state of Bahia, used as case studies, as well as semi structured interviews conducted with professionals of the State environmental agency. The results indicate opportunities for the adoption of clean technologies and management alternatives with the integration of $\mathrm{CP}$ in EIA.
\end{abstract}

Key words: Clean Production; Environmental impact assessment; Environmental management. 


\section{INTRODUÇÃO}

A Avaliação de Impacto Ambiental é um importante instrumento de política e gestão ambiental, utilizado no Brasil vinculado ao Licenciamento Ambiental e na etapa de planejamento da atividade. A AIA foi introduzida no Brasil em 1981 por meio da Lei da Política Nacional do Meio Ambiente e desde 1986 vem sendo exigida para empreendimentos causadores de significativa degradação ambiental, em geral empreendimentos de grande porte ou em áreas vulneráveis. No entanto, sendo o Brasil um país federativo, a aplicação desses instrumentos (Licenciamento e Avaliação de Impacto Ambiental) é de competência dos três níveis de governo: Federal (atividades nucleares, situadas entre dois estados ou transfronteiriços); Estadual (atividades de impacto regional) ou municipal (atividades de impactos locais), conforme consta numa Resolução do Conselho Nacional do Meio Ambiente (CONAMA, Resolução 237/97).

A AIA é uma ferramenta de caráter prévio, antecipatório e preventivo que visa ao equacionamento do conflito entre a necessidade de apropriação e utilização dos recursos naturais e a manutenção do padrão aceitável da qualidade ambiental, por meio do estabelecimento de procedimentos e atividades sequenciadas.

Nesse sentido, a AIA tem como objetivo: (a) dar suporte à decisão, buscando formas sustentáveis de desenvolvimento; (b) contribuir com a concepção e o planejamento de empreendimentos/atividades, visando projetos ambientalmente menos agressivos; (c) instrumentar a negociação social e, por fim, (d) instrumentar a gestão ambiental, por meio de compromissos assumidos pelo empreendedor (Sanchez, 2008). A Resolução CONAMA 001 de 23 de janeiro de 1986 (CONAMA, 1986), estabelece definições, responsabilidades, critérios e diretrizes que orientam o uso e implantação da AIA no Brasil e em diversos estados e municípios.

A efetividade desse instrumento, no entanto, tem sido objeto de questionamento de alguns estudos, que apontam dificuldades e deficiências em relação aos seus propósitos. Segundo Cashmore e colaboradores, (2004) a avaliação da chamada efetividade "substantiva" da AIA deveria focar três abordagens: a dimensão racional (a AIA como um exercício político racional), a dimensão decisória (a AIA como instrumento de decisão) e a dimensão da sustentabilidade (a AIA como instrumento para o desenvolvimento sustentável). Estes autores argumentam que a AIA pode ser utilizada numa perspectiva minimalista (levando à adoção de medidas mitigadoras fim-de-tubo) ou numa perspectiva mais ampla que buscaria evitar os impactos, considerando princípios da engenharia ambiental em todo ciclo do projeto.

Entre os estudos realizados sobre as deficiências dos Estudos de Impacto Ambiental no Brasil, destaca-se o realizado pelo Ministério Público Federal, (MPF, 2004), que identificou entre outras fragilidades relevantes:

a) Ausência de proposição de alternativas ou apresentação de alternativas de qualidade notoriamente inferior à selecionada;

b) Prevalência dos aspectos econômicos sobre os ambientais na seleção da alternativa;

c) Comparação das alternativas a partir de níveis diferentes de informações;

d) Falhas no diagnóstico ambiental em prover o nível adequado de detalhamento e análises; confiabilidade das fontes de dados e suficiência de informações sobre as metodologias utilizadas;

e) Incompleta descrição dos fatores ambientais e a ausência de integração dos dados.

As análises de alternativas constituem-se um dos pilares da AIA desde a sua concepção original. Esta etapa é também considerada por alguns autores como "a essência" da AIA. Os dispositivos normativos no Brasil reproduziram esta concepção ao determinar a necessidade de o Estudo de Impacto Ambiental realizar o estudo de alternativas tecnológicas e locacionais, como pode ser verificado na resolução 001/86 (art.5º do CONAMA (Brasil, 1986). Esta pretensão está 
explicitamente reafirmada no artigo $9^{\circ}$ da referida Resolução, ao preconizar que o EIA/Rima deverá recomendar a alternativa mais favorável.

A AIA foi concebida com a finalidade de oferecer suporte à decisão quanto ao planejamento de empreendimentos/ atividades potencialmente degradantes, com um enfoque da prevenção. A prevenção pretendida se materializa na seleção da melhor alternativa para o empreendimento em termos locacionais e tecnológicos. Assim, espera-se que a análise locacional propicie a identificação da alternativa compatível com as restrições ambientais e, sobretudo, com a capacidade de suporte do ambiente sob intervenção. A análise tecnológica deve propiciar a identificação da alternativa que incorpore a melhor tecnologia disponível considerando, entre outros aspectos, os princípios da Produção Limpa, expressa em termos da ecoeficiência.

No entanto, a aplicação do instrumento no Brasil, assim como em outros países, não cumpre com todas suas funções, ressentindo-se de uma abordagem mais ampla, capaz de fomentar a integração de outros instrumentos, tal como a Produção Limpa. Em um trabalho conduzido na China, Chen, Warren e Duan (1999) identificaram que a AIA tem falhado em proporcionar alternativas de Produção Limpa (PL), prevalecendo, como foco, a diminuição do impacto provocado pela poluição, ao invés da redução na fonte.

De fato, os instrumentos de gestão ambiental no Brasil, tais como o Licenciamento Ambiental e a AIA desempenham um papel fundamental na proposição de projetos alternativos, podendo fomentar e exigir práticas e tecnologias com ênfase na Produção Limpa, uma vez que têm como resultado uma série de exigências legais quanto à possíveis alternativas tecnológicas do projeto e medidas de prevenção, gestão e controle dos impactos ambientais negativos. Segundo Salvador et al (2000), a Produção Limpa e a AIA são considerados dois dos mais importantes processos para a proteção ambiental e, portanto, devem ser reforçados ao máximo.

A Produção Limpa pode ser definida como: “[...] contínua aplicação de uma estratégia ambiental preventiva integrada, aplicada a processos, produtos e serviços de forma a aumentar a ecoeficiência e reduzir riscos às pessoas e ao ambiente" (Unep, 1997, apud Cardoso, 2002). Compreende-se, portanto, a PL como uma abordagem que busca a ecoeficiência no uso dos recursos, o controle na fonte, a não-geração dos resíduos, a transparência da informação e o princípio da precaução (Greenpeace, 2001).

Partindo desta premissa, buscou-se, por meio de um estudo empírico, levantar pontos para aprimoramento da Avaliação de Impacto Ambiental que permitam potencializá-la como instrumento indutor da Produção Limpa. Para tanto, este artigo tomou como base os resultados de uma pesquisa que objetivou realizar um diagnóstico da aplicação da AIA no estado da Bahia, bem como elaborar proposições para sua inovação e aprimoramento visando assim alcançar uma maior efetividade da AIA, e, em última instância, contribuir para a sustentabilidade (Agra Filho et al, 2011).

Pretende-se, por meio deste estudo, estabelecer vínculos entre a AIA e a PL, estimulando, assim, que práticas e tecnologias apoiadas na Produção Limpa possam ser incorporadas ao processo de AIA.

\section{MÉTODO DE PESQUISA}

A pesquisa que gerou os dados para este artigo foi conduzida dentro de uma abordagem qualitativa, adotando como estratégias metodológicas: a análise documental, a realização de entrevistas e estudos de caso. Para tanto, foram selecionados quatro estudos de caso, de empreendimentos de tipologias diferentes (mineração, complexo hoteleiro, linha de transmissão de energia elétrica e empreendimento de imobiliário). Foi analisada a documentação do processo de Licenciamento Ambiental (Pareceres Técnicos, relatórios de inspeção de campo, Termos de Referência, Estudos de Impacto Ambiental- EIA, dispositivos normativos e legais aplicados, os condicionantes da Licença Ambiental etc.). Também foram conduzidas entrevistas 
semiestruturadas, com pessoas-chave do órgão ambiental, buscando obter dados relativos aos procedimentos adotados no processo de AIA e apreender a percepção dos respondentes e da instituição acerca da prática do instrumento, seus avanços e fragilidades.

\section{FUNDAMENTAÇÃO TEÓRICA: ABORDAGEM CONCEITUAL DA AVALIAÇÃO DE IMPACTO AMBIENTAL NA PERSPECTIVA DA PRODUÇÃO LIMPA}

Conceitualmente, a Avaliação de Impacto Ambiental pode ser definida da seguinte forma: "[...] é o instrumento que possibilita diagnosticar, avaliar e prognosticar as consequências ambientais relacionadas à localização, instalação, construção, operação, ampliação, interrupção ou encerramento de uma atividade ou empreendimento" - Decreto Estadual No 11.235/09, (Bahia, 2008, Art. 99 parágrafo único). Segundo Moreira (1992, p.33), a Avaliação de Impacto Ambiental é:

Instrumento de política ambiental, formada por um conjunto de procedimentos capaz de assegurar, desde o início do processo, que se faça um exame sistemático dos impactos ambientais de uma ação proposta (projeto, programa, plano ou política) e de suas alternativas, e que os resultados sejam apresentados de forma adequada ao público e aos responsáveis pela tomada de decisão, e por eles considerados. Além disso, os procedimentos devem garantir adoção das medidas de proteção do meio ambiente determinadas, no caso de decisão sobre a implantação do projeto.

A AIA foi concebida com base no conceito do impacto significativo, ou seja, empreendimentos/atividades que possam causar impactos ambientais significativos (expressivos, consideráveis, suficientemente grandes) devem ser objeto de Estudo de Impacto Ambiental (Sánchez, 2008). Desta forma, a AIA é organizada a fim de assegurar a realização de diversos procedimentos, que se constituem no chamado "processo de AIA" (Sánchez 2008). Este processo compreende o encadeamento das seguintes etapas:

a. a etapa inicial, que envolve os estudos realizados pelo proponente previamente à solicitação de uma autorização-licença a uma autoridade competente; a apresentação da proposta, com documentos exigidos pela autoridade ambiental; a decisão sobre a realização ou não do EIA (etapa de triagem ou screening), e a orientação desses estudos, o que implica o estabelecimento de um escopo do Estudo de Impacto Ambiental;

b. a etapa de realização dos estudos (EIA);

c. a etapa de análise/revisão dos estudos pela autoridade competente e sua discussão com os interessados (consultas, audiências, negociações, etc.);

d. etapa de decisão, que consiste na posição quanto a autorizações/ licenças;

e. a etapa de acompanhamento, que envolve a implementação de medidas, o monitoramento dos impactos e a gestão ambiental da atividade.

Denota-se, portanto, que a Avaliação de Impacto Ambiental compreende um processo sistemático de avaliação prévia dos empreendimentos/atividades causadores de potencial degradação ambiental, visando assegurar medidas de prevenção aos impactos ambientais significativos que possam advir das suas fases de planejamento, implantação, operação e ampliação. Esse processo deve ser regido por regulamentação e documentado, bem como envolver a participação dos diversos segmentos sociais: (I) o proponente da atividade; (II) a(s) autoridade(s) responsável (is); (III) consultores; (IV) público afetado e; (V) demais grupos de interesse etc.

\subsection{O papel do escopo e da preparação do EIA}

Revista de Gestão Social e Ambiental - RGSA, São Paulo, v. 6, n. 3, p. 129-141, set./dez. 2012. 
Para atingir os propósitos da AIA, cada etapa desempenha o seu papel fundamental. A definição do escopo, por exemplo, deve direcionar o processo de AIA para as questões fundamentais envolvidas na análise dos impactos potenciais da atividade e suas alternativas. Desta forma, um escopo adequado para o Estudo de Impacto Ambiental evita desperdícios de tempo e recursos (com a não realização de estudos muito extensos e focados para as questões chave). $\mathrm{O}$ escopo do EIA deve estabelecer hipóteses a serem verificadas nos estudos e questões a serem respondidas pelos mesmos (Sánchez, 2008). O conteúdo mínimo de um EIA, de acordo com a Resolução do Conselho Nacional de Meio Ambiente CONAMA 001/1986, deve conter: (a) a definição dos limites da área de influência direta e indireta; (b) um diagnóstico ambiental dos meios físico, biótico e socioeconômico; (c) análise dos impactos ambientais do empreendimento e de suas alternativas; (d) definição das medidas mitigadoras dos impactos negativos e elaboração de programas de acompanhamento e monitoramento.

Sendo o Estudo de Impacto Ambiental (EIA), o documento que fornece informações técnicas e análises sobre os impactos potenciais, alternativas e propostas de medidas, a sua elaboração é fundamental para a tomada de decisão sobre a viabilidade ambiental de um empreendimento/atividade. Buscando uma efetividade substantiva do instrumento, a definição do Escopo do EIA (Termos de Referência) e a sua elaboração deveria direcionar os estudos para alternativas de projetos com foco na Produção Limpa.

\subsection{O Feedback da etapa de acompanhamento dos impactos}

É importante observar que a AIA está fundamentada em estudos de previsões e aproximações, em que há incertezas, devido, entre outras razões, à dinâmica dos processos que ocorrem no ambiente e suas alterações, como também ao nível de conhecimento existente. Desta forma, para a análise da efetividade da AIA, é também fundamental a realização de estudos que foquem a etapa de pós-decisão, ou seja, o acompanhamento ou follow up. Este inclui: o monitoramento das condições ambientais; a fiscalização e a análise da eficácia das medidas para reduzir, eliminar ou compensar os impactos adversos; a verificação da precisão das previsões; a efetividade da gestão ambiental nos empreendimentos indicando possíveis ajustes; e o seu atendimento aos requisitos legais.

O acompanhamento dos impactos reais é uma das etapas mais precárias do processo de AIA, que faz com que o processo não seja cíclico. Na maior parte das vezes, o acompanhamento é precário e, quando realizado, não faz a retroalimentação necessária ao sistema de AIA para que este se aprimore continuamente. Os estudos de Wilson (1999), Arts, Morrison-Saunders (2001), Noble e Storey (2005) e Sadler (1996) indicam que esta deficiência é comum a diversos países. No Brasil, ainda são poucos os trabalhos sobre a etapa de pós-decisão, destacando-se os de Agra Filho e colaboradores (2007) e Santos e colaboradores (2010), que propõem metodologias para a análise dessa referida etapa. Um estudo em São Paulo levou a conclusão de que falhas nesta etapa da AIA decorriam tanto da ausência de fiscalização por parte dos órgãos ambientais quanto de outras deficiências ao longo do processo de AIA (Dias, 2001). O acompanhamento dos impactos deve retroceder ao processo de AIA, trazendo informações sobre efetividade das medidas implementadas, buscando o aprimoramento contínuo dos processos e da gestão, visando produzir bens e serviços de maneira mais limpa.

\subsection{Promoção da Produção Limpa pela AIA}

A Produção Limpa (PL) propõe um modelo de produção sustentável, por meio: da ecoeficiência dos processos; da minimização e otimização; da utilização de materiais renováveis e não-nocivos; da preservação da biodiversidade. Para tanto, a PL analisa toda a cadeia produtiva do produto, desde a seleção e produção da matéria-prima; passando pelo processo produtivo propriamente dito; pela utilização do produto pelo consumidor; pelo descarte do produto; até o final da vida útil (Greepeace, 2001). A Produção Limpa pressupõe quatro princípios fundamentais: o da

Revista de Gestão Social e Ambiental - RGSA, São Paulo, v. 6, n. 3, p. 129-141, set./dez. 2012. 
Prevenção (não-geração das emissões, pelo controle na fonte); a da Precaução (medidas de proteção, mesmo antes da comprovação científica do dano, e mudança do ônus da prova para o proponente); o da Integração (visão ampla do ciclo produtivo por meio de ferramentas como a Análise de Ciclo de Vida) e o do Controle democrático (acesso à informação aos interessados referentes a situações que envolvem o meio ambiente e segurança) (Furtado, 2000).

Como exemplos de alternativas para se alcançar a Produção Limpa, pode-se citar (Unep, 1997):

a) a substituição de matérias-primas e insumos por materiais menos tóxicos ou com maior tempo de vida;

b) diferentes estratégias para gerenciar, reduzir e otimizar o uso dos recursos ao invés de utilizar um novo recurso (ex: minimização do consumo de água e energia);

c) mudanças tecnológicas ou de layouts; substituição da tecnologia ou do processo, de forma a garantir eficiência no uso dos recursos e minimizar a geração de resíduos;

d) melhor controle do processo;

e) boas práticas operacionais para prevenir vazamentos e garantir cumprimento de instruções de trabalho;

f) reuso no próprio sitio (no mesmo processo ou em outras aplicações na própria atividade);

g) produção de subprodutos utilizáveis para reduzir a geração de resíduos e favorecer o reuso;

h) mudanças no design no produto, de forma a reduzir o consumo de recursos e as emissões;

i) melhoria da gestão, de forma a assegurar um ambiente de trabalho saudável e seguro com a colaboração dos trabalhadores, treinamento efetivo e desenvolvimento de parcerias com os stakeholders.

Tendo em vista o caráter prévio e preventivo da AIA, torna-se necessário potencializar os benefícios para a prevenção e precaução dos impactos potenciais negativos. O processo de AIA deve buscar analisar alternativas tecnológicas mais limpas, melhor eficiência no uso dos recursos naturais e localizações que ofereçam menor dano ao ambiente.

Segundo Salvador et al (2000), a Produção Limpa e o processo de AIA possuem uma grande interface no que diz respeito aos seus princípios, objetivos, práticas e procedimentos, sendo, portanto, considerados processos importantes para uma abordagem preventiva e integrada na busca da redução de problemas ambientais.

No estudo conduzido por Chen, Warren e Duan (1999), os mesmos concluíram que, na China, a AIA tem sido focada em soluções fim de tubo em detrimento da abordagem da Prevenção da Poluição. Esses autores apresentam alguns critérios para a avaliação da Produção Limpa de empreendimentos submetidos à AIA, como apresentados na figura 1 .

\begin{tabular}{|c|c|c|}
\hline & Critério para análise & Significado do critério \\
\hline \multirow[t]{5}{*}{$\begin{array}{l}\text { Matérias-primas e } \\
\text { insumos }\end{array}$} & Toxicidade & $\begin{array}{l}\text { Grau de impacto no ambiente causado por componentes } \\
\text { tóxicos das matérias-primas. }\end{array}$ \\
\hline & Impacto ecológico & $\begin{array}{l}\text { Grau de impacto ecológico causado pela extração de } \\
\text { matéria-prima. }\end{array}$ \\
\hline & Potencial de recuperação & $\begin{array}{l}\text { Grau de recuperação da matéria-prima para produção de } \\
\text { novas matérias-primas. }\end{array}$ \\
\hline & Intensidade energética & $\begin{array}{l}\text { Grau de consumo de energia para extração e produção de } \\
\text { matéria-prima. }\end{array}$ \\
\hline & $\begin{array}{l}\text { Potencial de reuso e } \\
\text { reciclagem }\end{array}$ & $\begin{array}{l}\text { Grau de reuso e reciclagem das matérias- primas que } \\
\text { podem causar problemas ambientais secundários. }\end{array}$ \\
\hline Produtos & Venda e distribuição & $\begin{array}{l}\text { Grau de impacto da venda, transporte e distribuição do } \\
\text { produto. }\end{array}$ \\
\hline
\end{tabular}

Revista de Gestão Social e Ambiental - RGSA, São Paulo, v. 6, n. 3, p. 129-141, set./dez. 2012. 


\begin{tabular}{|c|c|c|}
\hline & Consumo & $\begin{array}{l}\text { Grau de impacto causado pelo consumo do produto } \\
\text { (incluindo o consumo de energia e outros produtos durante } \\
\text { o uso). }\end{array}$ \\
\hline & Otimização da vida do produto & $\begin{array}{l}\text { Grau de otimização da vida do produto, (incluindo } \\
\text { aspectos técnicos e estéticos que influenciam os } \\
\text { consumidores). }\end{array}$ \\
\hline & Disposição & $\begin{array}{l}\text { Grau de impacto ambiental provocado pela disposição } \\
\text { final dos produtos. }\end{array}$ \\
\hline \multirow[t]{3}{*}{ Uso dos recursos } & Água & $\begin{array}{l}\text { Quantidade de água consumida, por quantidade de produto } \\
\text { produzido. }\end{array}$ \\
\hline & Energia & $\begin{array}{l}\text { Quantidade de energia consumida, por quantidade de } \\
\text { produto produzido. }\end{array}$ \\
\hline & Outros & $\begin{array}{l}\text { Quantidade de outros materiais consumidos, por } \\
\text { quantidade de produto produzido. }\end{array}$ \\
\hline \multirow[t]{6}{*}{$\begin{array}{l}\text { Geração de } \\
\text { poluentes }\end{array}$} & \multirow[t]{2}{*}{ Efluentes líquidos } & $\begin{array}{l}\text { Quantidade de efluentes gerados, por quantidade do } \\
\text { produto produzido. }\end{array}$ \\
\hline & & $\begin{array}{l}\text { Quantidade dos principais poluentes aquáticos gerados, } \\
\text { por quantidade de produto produzido. }\end{array}$ \\
\hline & \multirow[t]{2}{*}{ Emissões atmosféricas } & $\begin{array}{l}\text { Quantidade de emissões geradas, por quantidade de } \\
\text { produto produzido. }\end{array}$ \\
\hline & & $\begin{array}{l}\text { Quantidade dos principais poluentes atmosféricos gerados, } \\
\text { por quantidade de produto produzido. }\end{array}$ \\
\hline & \multirow[t]{2}{*}{ Resíduos sólidos } & $\begin{array}{l}\text { Quantidade de resíduos sólidos gerados, por quantidade de } \\
\text { produto produzido. }\end{array}$ \\
\hline & & $\begin{array}{l}\text { Quantidade dos principais poluentes sólidos gerados, por } \\
\text { quantidade de produto produzido. }\end{array}$ \\
\hline
\end{tabular}

Figura 1 - Critérios para Avaliação de Produção Limpa na AIA

Fonte: Chen, Warren e Duan (1999)

A integração entre a AIA e a PL representa uma possibilidade de reduzir os problemas e impactos ambientais causados pela implantação, operação e desativação dos empreendimentos/atividades. A elaboração de Estudos de Impacto Ambientais mais focados na produção limpa confere uma série de benefícios às empresas, uma vez que os conceitos de PL serão introduzidos na fase preliminar à implantação do empreendimento, ou seja, na fase do planejamento, permitindo, dessa forma, uma maior aderência da PL nas práticas adotadas futuramente pela empresa. Algumas vantagens dessa junção das empresas estão elencadas a seguir:

a. maior consciência ambiental dentro das empresas, o que pode vir a contribuir para o marketing e a competitividade da empresa;

b. aumento da eficiência energética e hídrica;

c. diminuição do uso de materiais;

d. aumento da eficiência na produção;

e. ganhos econômicos.

Nesse sentido, a Produção Limpa (PL), pautada na prevenção da poluição, quando estimulada pela AIA, instrumento de planejamento e prévio à implantação das atividades, pode levar a otimização e a ecoeficiência no uso dos recursos ambientais dos produtos, processos e serviços, reduzindo as emissões no ambiente.

Dessa forma, a AIA, na perspectiva da Produção Limpa, desponta como uma alternativa ambientalmente e economicamente atraente para o setor produtivo, possibilitando assim a busca por produtos e processos ambientalmente corretos. 


\subsection{A formulação e análise de alternativas na AIA com foco na PL}

Steinemann (2001) afirma que os EIA, em geral, apresentam uma abordagem de alternativa muito limitada, determinada por decisões previamente tomadas que não consideraram os impactos ambientais. Dessa forma, os estudos custosos e grandes falham em apontar pontos cruciais, incorporar a percepção do público e explorar alternativas ambientalmente melhores. Como proposição para aprimorar esta fase da AIA, a autora argumenta que a análise de alternativas deve ser realizada em dois momentos: a) quando da discussão dos objetivos do projeto e desenvolvimento e seleção de um escopo de alternativas "razoáveis" para os estudos; a b) quando da realização do EIA com análise detalhada de alternativas pré-selecionadas. Para as duas etapas, faz-se necessário a definição de critérios balizadores. Em ambos os momentos da discussão de alternativas na AIA, pôde-se estudar estratégias de Produção Limpa, seguindo, por exemplo, os critérios propostos por Chen, Warren e Duan (1999).

Embora a Resolução CONAMA nº 001, de 23 de janeiro de 1986, principal dispositivo normativo que orienta os órgãos ambientais e empresas no Brasil na elaboração de Estudos de Impacto Ambiental, enfatiza a necessidade de apresentação de alternativas tecnológicas e locacionais, não menciona a adoção de tecnologias limpas e ecoeficientes. Ao contrário disto, percebe-se, na análise desta norma orientadora, que a mesma induz as tecnologias fim de tubo, como pode ser percebido no inciso III do seu Artigo $6^{\circ}$ que trata do conteúdo do EIA:

Definição das medidas mitigadoras dos impactos negativos, entre elas os equipamentos de controle e sistemas de tratamento de despejos, avaliando a eficiência de cada uma delas (grifo nosso).

Desta forma, o que se percebe, é que, a AIA e o respectivo Licenciamento Ambiental (instrumentos vinculados no Brasil) não têm acarretado necessariamente em indução de alternativas com a ênfase na prevenção da geração do impacto ou dos resíduos. No entanto, cabe ressaltar que, sendo uma norma de 1986, é premente a necessidade de sua revisão, com vistas à incorporação, no seu conteúdo, de exigências quanto a tecnologias mais limpas, uso de fontes renováveis de energia, ecoeficiência no uso dos recursos e projetos mais ambientalmente amigáveis. Esta explicitação, que consta no documento legal de referência para aqueles que estão envolvidos com a prática do instrumento (consultores, órgão ambiental, empreendedores, demais partes interessadas), levaria muito provavelmente à adoção de alternativas sustentáveis.

É importante ressaltar que os dispositivos legais mais recentes vêm incorporando a abordagem da Produção Limpa e da ecoeficiência no uso dos recursos naturais. A Política de Meio Ambiente e de Proteção à Biodiversidade do Estado da Bahia, instituída pela Lei no 10.431 , de 20 de dezembro de 2006 e regulamentada pelo Decreto $n^{\circ} 11.235$ de 10 de outubro de 2008, estabelece no seus artigos $1^{\circ}$ e $2^{\circ}$, entre os seus princípios, objetivos e diretrizes, a observância, dos princípios da prevenção e da precaução; “[...] adoção de práticas, tecnologias e mecanismos que contemplem o aumento da eficiência ambiental na produção de bens e serviços, no consumo e no uso dos recursos ambientais". Além disso, "[...] otimização do uso de energia, matérias-primas e insumos visando à economia dos recursos naturais, à redução da geração de resíduos líquidos, sólidos e gasosos".

Faz-se necessário, portanto, o estabelecimento de novos dispositivos normativos ou que se faça a revisão dos atuais dispositivos relativos à AIA, que recomendem ou exijam a adoção de tecnologias mais limpas, entendendo-se que a regulação ambiental, juntamente com iniciativas voluntárias e outros instrumentos de gestão, desempenha um papel fundamental na melhoria do desempenho ambiental das atividades potencialmente impactantes.

\section{RESULTADOS E DISCUSSÃO}


A elaboração do Estudo de Impacto Ambiental (EIA) é a etapa mais importante da AIA, pois este se constitui em um documento imprescindível para a tomada de decisão, uma vez que norteia as decisões quanto à viabilidade ambiental do projeto e que podem, por sua vez, estimular o uso de tecnologias limpas e incentivar a adoção de práticas ecoeficientes em todas as fases de um empreendimento/atividade. Assim, os resultados das análises procedidas em etapas do EIA com grande interface com a Produção Limpa estão apresentados nos tópicos a seguir.

\subsection{A abordagem da caracterização do empreendimento na AIA}

A caracterização do empreendimento é uma etapa inicial do EIA em que o empreendedor disponibiliza informações e estima dados referentes à concepção do empreendimento, identificando e quantificando (quando necessário) itens, tais como as emissões atmosféricas; efluentes líquidos; resíduos sólidos; ruídos e vibrações; consumo de água e balanço hídrico; consumo de energia; materiais de insumos licenciados (madeira, areia, entre outros); mapas da localização e plantas do empreendimento; informações locacionais de layout da instalação; supressão da vegetação. Tais informações permitem a identificação e análise dos impactos ambientais decorrentes de suas fases de planejamento, implantação, operação e ampliação.

Essa etapa possibilita identificar e dimensionar as demandas por recursos naturais associadas à atividade, tornando possível uma avaliação da magnitude dos impactos do empreendimento, para assim, oportunizar a minimização do uso dos recursos naturais, bem como possibilitar a utilização da melhor tecnologia disponível/ecoeficiente. Assim, quando a caracterização do empreendimento é realizada de forma detalhada e responsável, torna possível o reconhecimento de oportunidades de aplicação dos princípios da Produção Limpa e adoção de tecnologias limpas.

A partir do Estudo realizado no Estado da Bahia, verificou-se que a etapa de caracterização do empreendimento é conduzida de forma limitada, uma vez que foram observadas estimativas genéricas ou, até mesmo, a ausência de dados quali-quantitativos relativos ao consumo de água, energia elétrica, geração de efluentes líquidos e resíduos sólidos. No que se refere ao balanço hídrico e energético, os EIA analisados não consideraram nenhum desses aspectos, bem como não foram identificadas oportunidades para minimização do consumo de água e energia, comprometendo assim, a análise da melhoria da eficiência hídrica e energética.

Predominou a ausência de informações acerca dos insumos que serão utilizados nas atividades. Dessa forma, a identificação de oportunidades para substituições por outros insumos mais sustentáveis e o incentivo às compras verdes ficaram impossibilitadas. Constatou-se ainda a apresentação de soluções convencionais para o abastecimento de água e tratamento das águas servidas, apoiadas nas medidas fim de tubo. Esta prática não abre oportunidades para o aprimoramento e surgimento de novas tecnologias ambientalmente mais interessantes (tecnologias mais limpas).

A análise dos dados desta pesquisa indicou deficiências com relação às práticas adotadas pelo órgão ambiental, de tal forma que a ausência de determinados itens foram induzidos por falta de indicação no Termo de Referência, evidenciando a fragilidade no cumprimento da função deste item em fornecer uma melhor caracterização do empreendimento, o que impossibilitou uma melhor identificação dos impactos em etapa posterior do documento. Outra fragilidade identificada foi com relação à etapa de revisão do EIA, os pareceres técnicos analisados, em geral, apresentaram uma abordagem muito sucinta, com poucos dados quantitativos sobre a caracterização do empreendimento que permitissem analisar, mais precisamente, o seu potencial impacto.

Dessa forma, a pesquisa constatou que a etapa de caracterização do empreendimento não vem cumprindo adequadamente sua função, pois não apresenta informações suficientes que caracterizem as ações e suas prováveis consequências ao meio ambiente. Esta prática compromete o papel desta etapa do EIA, pois não estima devidamente o porte do empreendimento e não identifica oportunidades de aplicação de tecnologias limpas e, sobretudo, da sustentabilidade hídrica e da eficiência energética, além de não possibilitar o emprego por outros insumos mais sustentáveis.

Revista de Gestão Social e Ambiental - RGSA, São Paulo, v. 6, n. 3, p. 129-141, set./dez. 2012. 
Assim, compreende-se que, tanto os EIA quanto os pareceres, não incorporaram os conceitos da Produção Limpa, da prevenção da poluição e ecoeficiência no uso dos recursos, o que fica evidente quando são apresentadas soluções convencionais apoiadas nas medidas fim de tubo, o que, por sua vez, restringiu a efetividade do EIA quanto à elaboração de melhores projetos do ponto de vista ambiental.

\subsection{A discussão das alternativas na AIA}

A etapa de formulação de alternativas consiste na apresentação das alternativas tecnológicas, locacionais e de concepção, a fim de identificar e selecionar alternativas a serem estudadas no EIA, visando a comparação, bem como estimular a formulação de alternativas inovadoras com foco na prevenção da poluição e tecnologias limpas.

Este estudo, conduzido na Bahia, constatou que um grande desafio da AIA tem sido contemplar uma análise de alternativas que permita um confronto entre as mesmas com um grau mínimo de informações sobre tecnologias e condições ambientais que possibilitem essa comparação e suas implicações ambientais. Sem esse confronto, a AIA se torna um instrumento oneroso e de grande consumo de tempo sem atingir os seus objetivos. Dentro desse desafio, deve-se priorizar, desde a fase de definição do escopo do EIA, até a indução de alternativas com foco na Produção Limpa como requisito obrigatório. Nesse propósito, torna-se indispensável que as informações sobre a caracterização do empreendimento forneçam elementos que permitam o confronto das alternativas tecnológicas em análise.

Algumas barreiras identificadas para se melhorar a etapa de análise de alternativas na AIA buscando o foco da PL são: carência de estudos de base (baseline) que acarreta na necessidade de levantamentos e geração de dados primários por parte da equipe que elabora os estudos; a falta da sistematização dos dados ambientais produzidos por estudos prévios e pela própria gestão ambiental dos empreendimentos; pressões do setor econômico e governamental para dar celeridade aos processos de Licenciamento; desconhecimento por parte das equipes que realizam e analisam os Estudos de alternativas tecnológicas ambientalmente inovadoras com foco em Produção Limpa; entre outras. Desta forma, considera-se como um dos passos fundamentais, que as instituições governamentais e empresas que realizam os EIA busquem um maior conhecimento das tecnologias limpas disponíveis para cada tipologia, para solicitar e examinar estas soluções nos estudos de alternativas do EIA.

$\mathrm{Na}$ pesquisa no estado da Bahia, observou-se que a abordagem sobre a seleção de alternativas nos EIA está circunscrita às justificativas de uma alternativa locacional preferencial e das dispensas de algumas possibilidades. Eventualmente, são consideradas alternativas tecnológicas, mas normalmente não focadas em redução na fonte, ecoeficiência, reuso de água, energia limpa, análise do ciclo de vida e fechamento do ciclo. Assim, predomina o procedimento de avaliação de uma única alternativa, sem consideração, na grande maioria das vezes de alternativas de prevenção da poluição, nos termos aqui definidos e que constam na figura 1. Diante dessa prática, constata-se a eliminação do confronto de alternativas no processo de análise. Dessa forma, configura-se um reducionismo da aplicação da AIA, que se torna reativa ao se restringir à identificação de medidas para atenuar os danos provocados pela atividade ao invés de buscar caminhos para sua não-geração. Assim, têm-se uma grave fragilidade na qualidade da avaliação e, sobretudo, um sério comprometimento da efetividade de aplicação do instrumento. É preciso compreender que um empreendimento que passa por um processo de Licenciamento Ambiental necessariamente terá que implementar medidas de gestão dos impactos ambientais. Desta forma, a AIA pode ser vista como uma aliada na futura gestão do empreendimento, muitas vezes realizada de forma sistemática por meio de um Sistema de Gestão Ambiental. Esta compreensão mais abrangente do instrumento acarretará em maior cuidado com a etapa de análise de alternativas tecnológicas e locacionais, se traduzindo na maior efetividade "substantiva", como abordada por Cashmore at al (2004).

Revista de Gestão Social e Ambiental - RGSA, São Paulo, v. 6, n. 3, p. 129-141, set./dez. 2012. 


\subsection{Análises das condicionantes de Licença Ambiental de empreendimentos submetidos à AIA no estado da Bahia quanto à Produção Limpa}

A figura 2 mostra a análise referente às condicionantes de Licença Ambiental nos quatro Estudos de Caso analisados, quanto à sua natureza, utilizando os seguintes critérios: (medidas de controle convencional; medidas de prevenção da geração de impacto; medidas compensatórias; programa de acompanhamento/monitoramento; outras medidas de gestão e outros quesitos normativos) para as quatro tipologias analisadas. Como base na análise dos dados pode-se fazer as seguintes considerações:

As exigências predominantes das condicionantes são medidas de caráter geral de gestão ambiental e de cunho administrativo, envolvendo comprovantes legais ou reafirmando restrições normativas vigentes.

Entre os condicionantes que se referem à exigência de medidas mitigadoras, observa-se a predominância de medidas chamadas de "controle convencional", sendo as medidas de prevenção focadas na não-geração da poluição ou do impacto, conforme critérios sugeridos por Chen, Warren e Duan (1999), consideradas ainda minoritárias.

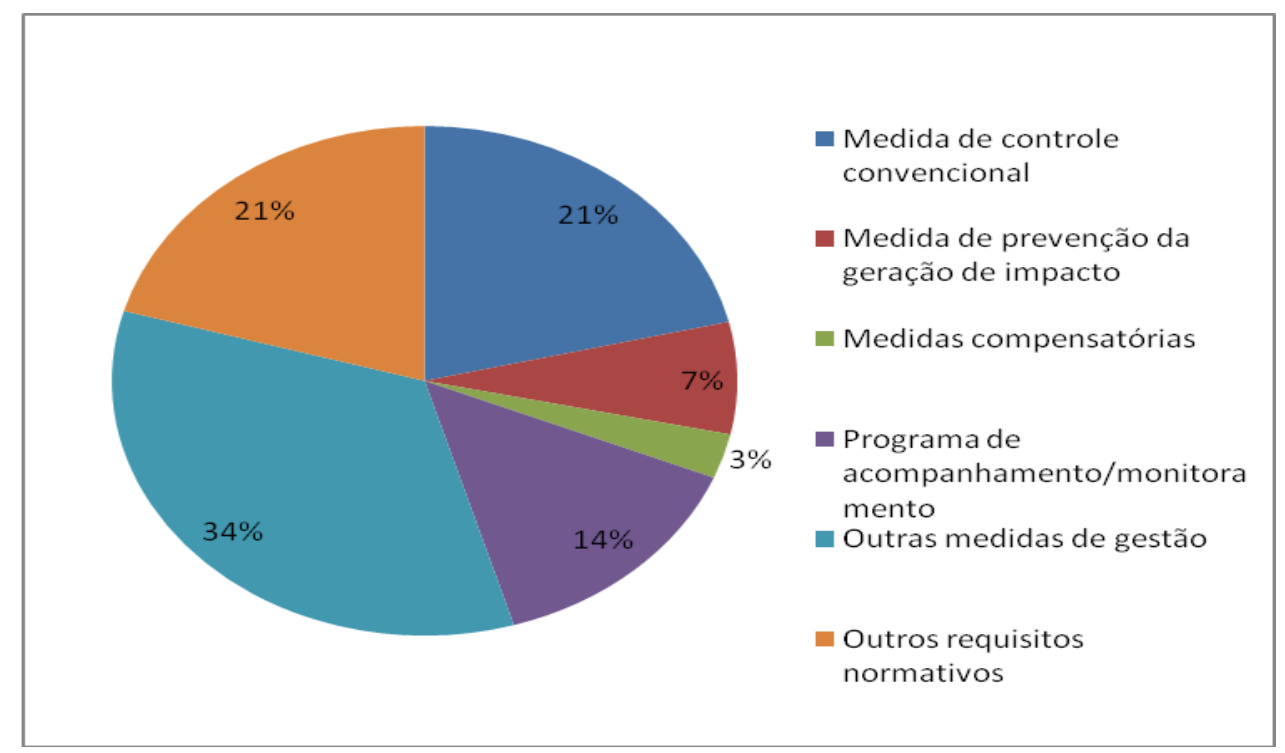

Figura 2: Natureza dos condicionantes nas quatro tipologias analisadas.

Fonte: Agra Filho, et al (2011).

\section{CONSIDERAÇÕES FINAIS}

Considera-se que a AIA tem um potencial para gerar melhores resultados tanto para o ambiente, quanto para a sociedade e mesmo para a própria gestão de impactos ambientais pelas empresas, no entanto, este potencial não está sendo utilizado. Com base nos dados da pesquisa, constata-se que a AIA tem falhado no seu potencial de produzir alternativas mais condizentes com a sustentabilidade ambiental no que se refere à minimização do uso dos recursos e não geração dos impactos. Essa deficiência é corroborada pela omissão do Termo de Referência em relação à necessidade de considerar a análise de alternativas tecnológicas. Torna-se necessário, portanto, ser exigido no Termo de Referência que orienta os estudos, a análise e o confronto de alternativas com foco na Produção Limpa, com critérios e indicadores de análise.

Por meio da análise dos estudos de caso, pode-se também concluir que as medidas propostas, que resultam de estudos de impactos ambientais muitas vezes custosos e demorados, não têm priorizado a prevenção dos impactos, prevalecendo, portanto, as chamadas medidas de controle ou fim de tubo, o que caracteriza a abordagem "minimalista" da AIA citada por Cashmore et al (2004). 
A adoção de estudo de casos para a realização da pesquisa possui uma limitação inerente a este procedimento metodológico. Além disso, a impossibilidade de se proceder a uma avaliação expost dos casos estudados representa outro aspecto restritivo dos resultados da pesquisa desenvolvida. Nesse sentido, recomenda-se uma complementação da pesquisa, considerando a fase de acompanhamento dos empreendimentos, de forma que se tenham maiores elementos de aprimoramento dos procedimentos praticados e, sobretudo, quanto à pertinência das metodologias de avaliação utilizadas.

\section{REFERÊNCIAS}

Agra Filho, S. S., Marinho, M. M. de O., Santos, J. O. (2007). Avaliação de impacto ambiental (AIA): uma proposta metodológica para análise de efetividade de aplicação através da avaliação expost. in: Congresso de Engenharia Sanitária e Ambiental -Abes, 24, Belo Horizonte. Anais do Congresso de Engenharia Sanitária e Ambiental-ABES, 24.

Agra Filho, S. S., Marinho, M. M. De O., Orrico, S. M., Cardoso, V. B. S., Santos, F.C., Machado, L. B., Cunha, M. A., Santos, J. O., Lopes, T. G. R.(2011). Relatório Final - Diagnóstico dos procedimentos de avaliação de impacto ambiental no estado da Bahia e propostas de aprimoramento. Relatório de Pesquisa do Convênio Universidade Federal da Bahia - UFBA / Instituto do Meio Ambiente - IMA. Junho.

Arts, J. P. C., Morrison Saunders. A.(2011). Environmental impact assessment follow-up: good practice and future directions. In: Workshop at the IAIA 2000 conference. Impact Assessment and Project Appraisal, Guildford, 19(3), 175-185.

Bahia.(2008). Decreto Estadual $n^{\circ}$ 11.235. Aprova o Regulamento da Lei $n^{o} 10.431$, de 20 de dezembro de 2006, que institui a Política de Meio Ambiente e de Proteção à Biodiversidade do Estado da Bahia, e da Lei $n^{o}$ 11.050, de 06 de junho de 2008, que altera a denominação, a finalidade, a estrutura organizacional e de cargos em comissão da Secretaria de Meio Ambiente e Recursos Hídricos - SEMARH e das entidades da Administração Indireta a ela vinculadas; e dá outras providências. Salvador: D.O., 11/10/2008.

Cardoso, L. M. F.(2002). Indicadores de produção limpa: uma proposta para análise de relatórios ambientais de empresas, Dissertação, Mestrado Profissional em Gerenciamento e Tecnologia Ambiental no Processo Produtivo- Meplim, UFBA.

Cashmore M. et al.(2004). The interminable issue of effectiveness: substantive purpose, outcomes and research challenges in the advancement of environmental impact assessment theory. In: Impact Assessment and Project Appraisal, 22(4), 295-310.

Chen. W., Warren, K.A., Duan, N.(1999). Incorporating cleaner production analysis into environmental impact assessment in China. In: Environmental Impact Assessment Review, Beijing, 19(5), 457-476.

Dias, E. G. C. S. (2001). Avaliação de impacto ambiental de projetos de mineração no Estado de São Paulo: a etapa de acompanhamento. 303p (Tese de Doutorado), Universidade de São Paulo, Escola Politécnica. Recuperado em: nov. 2010, de: $<$ http://sustentavel.inf.br/anexos/publicacao/rio10_miolo.pdf $>$.

Furtado, J. S.(2000). Administrando a ecoeficiência. Novembro. 
Greenpeace (2001). What is clean production? Recuperado em jul.2011, de: <http://teclim.ufba.br/jsf/producaol/greenpeace\%20cpb.PDF>.

MPF(2004). Deficiências em estudos de impacto ambiental: síntese de uma experiência. Brasília. Ministério Público Federal. $4^{\mathrm{a}}$ Câmara de Coordenação e Revisão: Escola Superior do Ministério Público da União, Brasil.

Moreira, I. V. D. (1992). (Compiladora). Vocabulário básico de meio ambiente. (4ª ed.) Rio de Janeiro-RJ. Serviço de Comunicação Social da Petrobrás.

Noble, B., Storey, K. (2005). Towards increasing the utility of follow-up in Canadian EIA. In: Environmental Impact Assessment Review, 25, 163-180.

Sadler, B. (1996). Environmental assessment in a changing world: evaluating practice to improve performance. Ottawa: Ministry of Supply and Services.

Santos, J. O. Andrade, J. C. S., Marinho. M. M. O. E Agra Filho, S. S.(2010). O Papel da etapa de acompanhamento para o processo de avaliação de impacto ambiental: um estudo em empreendimentos no Estado da Bahia. In: Simpósio Ítalo-Brasileiro de Engenharia Sanitária e Ambiental, 10, Maceió.

Salvador, N. N. B., Glasson J., Piper, J.M,(2000). Cleaner production and environmental impact assessment: a UK perspective Journal of Cleaner Production, 8, 127-132.

Sánchez, L. E. (2008). Avaliação de impacto ambiental: conceitos e métodos. São Paulo: Oficina de Textos.

Steinemann. A. (2001). Improving alternatives for environmental impact assessment. In: Environmental Impact Assessment Review, 21, 3-21.

Unep, Ie. (1997). Unep's global environment outlook, current changes in approaches to environmental policy: cleaner and leaner production. Recuperado em agosto 2011, de: <http://www.unep.org/GEO/geo1/ch/ch3_3.htm>.

Wilson, L.(1999). A practical method for environmental impact assessment. In: Environmental Impact Assessment Review, New York, 18, 59-71.

Recebido em: 12/12/2011

Publicado em: 21/12/2012 